\title{
Mango modulates body fat and plasma glucose and lipids in mice fed a high-fat diet
}

\author{
Edralin A. Lucas ${ }^{1 *}$, Wenjia $\mathrm{Li}^{1}$, Sandra K. Peterson ${ }^{1}$, Angela Brown ${ }^{1}$, Solo Kuvibidila ${ }^{1}$, \\ Penny Perkins-Veazie ${ }^{2}$, Stephen L. Clarke ${ }^{1}$ and Brenda J. Smith ${ }^{1}$ \\ ${ }^{1}$ Department of Nutritional Sciences, Oklahoma State University, Stillwater, 422 HES, OK 74078, USA \\ ${ }^{2}$ Department of Horticultural Science, North Carolina State University Research Campus, Kannapolis, NC 28081, USA
}

(Received 30 June 2010 - Revised 19 January 2011 - Accepted 15 March 2011 - First published online 28 June 2011)

\begin{abstract}
Consumption of fruits and vegetables has been investigated for their role in the prevention of many chronic conditions. Among the fruits, mango provides numerous bioactive compounds such as carotenoids, vitamin $\mathrm{C}$ and phenolic compounds, which have been shown to have antioxidant and anti-inflammatory properties. The present study examined the effects of dietary supplementation of freeze-dried mango pulp, in comparison with the hypolipidaemic drug, fenofibrate, and the hypoglycaemic drug, rosiglitazone, in reducing adiposity and alterations in glucose metabolism and lipid profile in mice fed a high-fat (HF) diet. Male C57BL/6J mice were randomly divided into six treatment groups (eight to nine/group): control (10\% energy from fat); HF ( $60 \%$ energy from fat); HF +1 or $10 \%$ freeze-dried mango $(\mathrm{w} / \mathrm{w}) ; \mathrm{HF}+$ fenofibrate $(500 \mathrm{mg} / \mathrm{kg}$ diet $) ; \mathrm{HF}+$ rosiglitazone $(50 \mathrm{mg} / \mathrm{kg}$ diet $)$. After 8 weeks of treatment, mice receiving the HF diet had a higher percentage body fat $(P=0.0205)$ and epididymal fat mass $(P=0.0037)$ compared with the other treatment groups. Both doses of freeze-dried mango, similar to fenofibrate and rosiglitazone, prevented the increase in epididymal fat mass and the percentage of body fat. Freeze-dried mango supplementation at the 1\% dose improved glucose tolerance as shown by approximately $35 \%$ lower blood glucose area under the curve compared with the HF group. Moreover, freeze-dried mango lowered insulin resistance, as indicated by the homeostasis model assessment of insulin resistance, to a similar extent as rosiglitazone and modulated NEFA. The present findings demonstrate that incorporation of freeze-dried mango in the diet of mice improved glucose tolerance and lipid profile and reduced adiposity associated with a HF diet.
\end{abstract}

Key words: Mango: Glucose: Diabetes: Cholesterol: High-fat diet

Obesity continues to be a major public health issue in the USA and worldwide ${ }^{(1,2)}$. Parallel to the increase in obesity is a rise in obesity-related chronic conditions such as type 2 diabetes and CVD. CVD continues to be the leading cause of death worldwide $^{(3,4)}$ and factors contributing to the development of CVD include the consumption of a high-fat (HF) diet, hyperglycaemia, dyslipidaemia and visceral adiposity ${ }^{(5-7)}$. Pharmacological therapies, dietary interventions and lifestyle modifications such as routine physical activity independently or in combination are capable of improving glycaemic control and lipid profiles. For patients unable to control the progression of diabetes or dyslipidemia through lifestyle modifications, pharmacological approaches may be necessary to control the development of these disorders.

Among the pharmacological options for treating hyperglycaemia and hyperlipidaemia, are a widely used class of drugs that function as agonists for $\operatorname{PPAR}^{(8)}$. PPAR are a family of ligand-activated nuclear receptor proteins capable of regulating the expression of genes involved in macronutrient metabolism and cellular differentiation ${ }^{(8-10)}$. There are three family members of the PPAR nuclear receptors identified: $\alpha, \beta / \delta$ and $\gamma$. PPAR- $\alpha$ agonists (e.g. fenofibrate) regulate genes involved in $\beta$-oxidation, ketogenesis, fatty acid synthesis and lipoprotein metabolism ${ }^{(8-10)}$. On the other hand, PPAR- $\gamma$ agonists (e.g. thiazolidinediones) improve insulin sensitivity in tissues such as adipose tissue and skeletal muscle by up-regulating glucose uptake ${ }^{(8-11)}$. Unfortunately, the use of fenofibrate may be associated with undesirable adverse events including dermatological problems, gastrointestinal distress, muscle pain, sweating and dizziness ${ }^{(12)}$. In contrast, potential side effects associated with the use of thiazolidinediones include fluid retention, heart failure and increased incidence of fracture ${ }^{(11)}$. Because of these adverse

Abbreviations: ACC- $\alpha$, acetyl-CoA carboxylase; ACOX, acyl CoA oxidase; FATP5, fatty acid transport protein 5; HF diet, high-fat diet; HOMA-IR, homeostasis model assessment of insulin resistance; MCAD, medium-chain acyl-CoA dehydrogenase.

*Corresponding author: Dr E. A. Lucas, fax +1 405744 1357, email edralin.a.lucas@okstate.edu 
effects, alternative treatment options are being explored for improving blood glucose control and lipid profiles.

Natural bioactive compounds found in foods offer a more appealing therapeutic option for many chronic diseases ${ }^{(13,14)}$. In particular, fruits and vegetables rich in phytochemicals have been investigated for their potential health benefits ${ }^{(15-18)}$. Among these fruits, mango (Mangifera indica L.) provides a number of well-known bioactive compounds such as carotenoids, vitamin $\mathrm{C}$ and phenolic compounds that have been shown to exhibit both antioxidant and anti-inflammatory properties $^{(19)}$. For example, the aqueous extract of the stem bark and leaves of mango was shown to effectively lower blood glucose in streptozotocin-induced diabetic rats ${ }^{(20,21)}$ and glucose-induced hyperglycaemia in rats and mice ${ }^{(22,23)}$. Mango stem bark extract has been demonstrated to exhibit anti-inflammatory properties by inhibiting egg albumininduced paw oedema in rats ${ }^{(20)}$. Furthermore, mango juice has been shown to inhibit free radical production and neoplastic transformation in BALB/3T3 and HL-60 cells, demonstrating potent antioxidant and anti-cancer properties ${ }^{(24)}$. Studies focused on polyphenolic components of the mango fruit, quercetin and the aglycone derivative of mangiferin (i.e. norathyriol), have revealed that these components inhibit the activation of all three isoforms of PPAR ${ }^{(25)}$. However, to our knowledge, there are no studies exploring the effects of dietary supplementation with mango fruit on CVD risk factors in the context of a high fat diet. Therefore, the present study was designed to investigate the effects of freeze-dried mango fruit (pulp) on body composition, glucose tolerance and lipid profiles in mice fed a high fat diet and to compare the response to fenofibrate and rosiglitazone.

\section{Methods}

\section{Animals and dietary treatments}

A total of fifty-two, 3-month-old, C57BL/6J male mice were purchased from Harlan Teklad (Indianapolis, IN, USA). Animal handling and procedures were approved by the Institutional Animal Care and Use Committee at Oklahoma State University. The mice were acclimated to a standardised powdered rodent diet (AIN 93M; control) ${ }^{(26)}$ for $3 \mathrm{~d}$. After acclimation, the mice were weighed and randomly divided into six dietary treatment groups (eight to nine mice/group): control; $\mathrm{HF}$ diet; $\mathrm{HF}+1$ or $10 \%(\mathrm{w} / \mathrm{w})$ freeze-dried mango pulp; $\mathrm{HF}+$ fenofibrate $(500 \mathrm{mg} / \mathrm{kg}$ diet; Cayman Chemicals, Ann Arbor, $\mathrm{MI}, \mathrm{USA})$; and $\mathrm{HF}+$ rosiglitazone $(50 \mathrm{mg} / \mathrm{kg}$ diet; Cayman Chemicals). The mice were housed in groups of four or five mice/cage. The HF diets were based on the formulation of Molnar et $a l .{ }^{(27)}$ and adjusted to have the same macronutrient composition, as well as $\mathrm{Ca}$ and $\mathrm{P}$ content (Table 1). The energy contribution of the control $v$. HF diets was: fat (9.5 v. $58.9 \%)$, carbohydrates $(75.8 v .27 \cdot 7 \%)$ and protein $(14.7$ v. $13.4 \%)$.

Mangoes (Tommy Atkins variety) were obtained from US importers, ripened to a soluble solids content of $>10 \%$ and peeled. A portion of the mango pulp was used for characterisation of ascorbic acid, carotenoids and phenolic compounds ${ }^{(28)}$, and the remainder was freeze-dried, ground and analysed for its nutrient composition before incorporation into the powdered diet at 1 or $10 \%$ concentration by weight. The doses of freeze-dried mango were based on our earlier animal study with dried plum ${ }^{(29)}$ and those of others using freeze-dried blueberries ${ }^{(30,31)}$, freeze-dried strawberries ${ }^{(30)}$

Table 1. Composition of the experimental diets

\begin{tabular}{lcccc}
\hline Ingredient (g/kg diet) & $\begin{array}{c}\text { Normal diet } \\
\text { (AIN-93M) }\end{array}$ & $\begin{array}{c}\text { High-fat } \\
\text { diettł }\end{array}$ & $\begin{array}{c}\text { High-fat diet }+1 \% \\
\text { mango }\end{array}$ & $\begin{array}{c}\text { High-fat diet }+10 \% \\
\text { mango }\end{array}$ \\
\hline Mango§ll & 0 & 0 & 10 & 100 \\
$\quad$ Total carbohydrate & 720 & 370 & 370 & 370 \\
$\quad$ Maize starch & 620 & 100 & 94 & $25 \cdot 2$ \\
$\quad$ Sucrose & 100 & 270 & 270 & 270 \\
Total fat & 40 & 350 & 350 & 350 \\
$\quad$ Soyabean oil & 40 & 40 & $39 \cdot 4$ & 33.5 \\
$\quad$ Lard & 0 & 310 & 310 & 310 \\
Total protein & 140 & 180 & 180 & 180 \\
$\quad$ Casein & 140 & 180 & $179 \cdot 6$ & $176 \cdot 1$ \\
Total fibre & 50 & 50 & 50 & 50 \\
Cellulose & 50 & 50 & $49 \cdot 6$ & 31 \\
Vitamin mix (AIN 93VX) & 10 & 10 & 10 & 10 \\
Mineral mix (AIN 93 MX) & 35 & 35 & 35 & 35 \\
Choline bitartrate & 2.5 & 2.5 & 2.5 & 2.5 \\
L-Cysteine & 1.8 & 1.8 & 1.8 & 1.8 \\
tert-Butylhydroquinone & 0.008 & 0.008 & 0.008 & 0.008 \\
Total energy (kJ/100 g diet) & 1585 & 2297 & 2313 & 2284
\end{tabular}

* Based on AIN-93M formulations with $75.8,14.7$ and $9.5 \%$ of total energy coming from carbohydrate, protein and fat, respectively ${ }^{(26)}$.

$\dagger$ High-fat diet was based on formulation of Molnar et al. ${ }^{(27)}$ with $27 \cdot 7,13.4$ and $58.9 \%$ of total energy coming from carbohydrate, protein and fat, respectively.

$\ddagger$ Rosiglitazone and fenofibrate were from Cayman Chemicals (Ann Arbor, MI, USA) and added to the high-fat diet at a dose of 50 and $500 \mathrm{mg} / \mathrm{kg}$ diet, respectively.

§Freeze-dried Tommy Atkins variety mango with the following nutrient composition as analysed by NP Analytical Laboratories (St Louis, MO, USA): carbohydrates, $74.8 \mathrm{~g} / 100 \mathrm{~g}$; protein, $3.9 \mathrm{~g} / 100 \mathrm{~g}$; fat, $6.5 \mathrm{~g} / 100 \mathrm{~g}$; fibre, $3.8 \mathrm{~g} / 100 \mathrm{~g}$; Ca, $0.0424 \mathrm{~g} / 100 \mathrm{~g} ; \mathrm{P}, 0.0941 \mathrm{~g} / 100 \mathrm{~g}$.

\| Other bioactive compounds present in the freeze-dried Tommy Atkins variety mango used in the study: ascorbic acid, $109.2 \mathrm{mg} / 100 \mathrm{~g}$; $\beta$-carotene, $28.3 \mathrm{mg} / 100 \mathrm{~g}$; total phenolic, $154.1 \mathrm{mg}$ of gallic acid equivalents $/ 100 \mathrm{~g}$; gallotanin, $424.4 \mathrm{mg} / 100 \mathrm{~g}$; mangiferin, $10.4 \mathrm{mg} / 100 \mathrm{~g}$; ellagic acid, $6.4 \mathrm{mg} / 100 \mathrm{~g}^{(28)}$.

१ Analysed by NP Analytical Laboratories. 
and dehydrated apples ${ }^{(32)}$ that investigated the effects of these fruits on clinical parameters. Based on the limited information available with freeze-dried mango pulp, we chose to explore the effect of the 1 and $10 \%$ doses. The dose and mode of administration of rosiglitazone $(50 \mathrm{mg} / \mathrm{kg}$ diet $)$ and fenofibrate ( $500 \mathrm{mg} / \mathrm{kg}$ diet) were based on the studies by Chao et al. ${ }^{\text {(33) }}$ and Guerre-Millo et al. ${ }^{(34)}$.

Ad libitum food and deionised water were provided. Food intake was monitored daily for 8 weeks during the midportion of the light cycle. Pre-weighed food was placed in a food bowl, measured on a per cage basis, and food intake was determined as g consumed/d. The mice were weighed weekly. Feed efficiency was calculated as follows: mg of body weight gain/cage per kJ of food consumed per cage.

\section{Glucose tolerance test}

At week 7, a glucose tolerance test was performed. From each group, six mice were randomly selected and fasted for $12 \mathrm{~h}$. The mice were injected intraperitoneally with 20\% glucose solution ( $2 \mathrm{~g} / \mathrm{kg}$ body weight). Blood glucose concentration was determined in tail blood samples taken at $0,5,15,30$, 60 and $120 \mathrm{~min}$ after glucose injection using a glucose testing kit (Onetouch Ultra; LifeScan, Inc., Milpitas, CA, USA). To examine glucose tolerance, differences in blood glucose concentration between groups at each time point were evaluated, and the area under the curve (AUC) for glucose was calculated by the trapezoidal rule ${ }^{(35)}$.

\section{Necropsy and tissue processing}

At the end of the 8 weeks of dietary treatment, the mice were fasted for $12 \mathrm{~h}$, weighed and injected with a ketamine/xylazine cocktail ( 80 and $8 \mathrm{mg} / \mathrm{kg}$ body weight, respectively). Body composition was determined using a GE Lunar Piximus (Fitchburg, WI, USA). Blood was collected from the carotid artery into EDTA-coated tubes. Plasma was obtained after centrifugation and stored at $-80^{\circ} \mathrm{C}$ for later analyses. Epididymal fat, liver, spleen and kidneys were collected, weighed, snap-frozen and stored at $-80^{\circ} \mathrm{C}$.

\section{Clinical analyses}

An Alfa Wassermann (West Caldwell, NJ, USA) clinical chemistry analyser was used to determine plasma concentrations of glucose, NEFA, total cholesterol, HDL and TAG. Kits were purchased from Alfa Wasserman except for NEFA (Wako Diagnostics, Richmond, VA, USA) and the manufacturer's instructions were strictly followed.

ELISA kits from Linco Research (St Charles, MO, USA) were used to determine plasma concentrations of leptin, adiponectin and insulin.

Non-HDL-cholesterol concentrations were calculated by subtracting HDL from total cholesterol. Insulin resistance was estimated by the homeostasis model assessment of insulin resistance (HOMA-IR) as described previously ${ }^{(36)}$ :

HOMA-IR $=($ fasting insulin $(\mu \mathrm{U} / \mathrm{ml}) \times$ fasting glucose $(\mathrm{mmol} / \mathrm{l})) / 22 \cdot 5$.

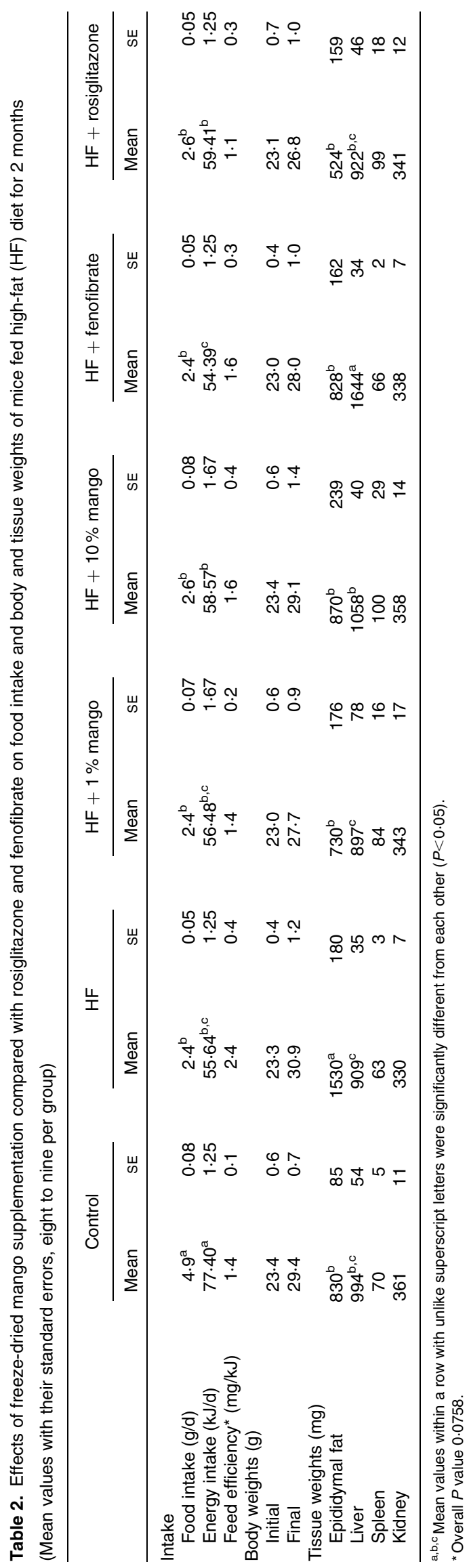


Although originally developed and validated in human subjects, it has been shown that HOMA-IR can be used to estimate insulin sensitivity and resistance in mice ${ }^{(37)}$.

\section{RNA isolation and gene expression}

RNA was extracted from the liver and adipose tissue (six per group) using STAT60 (TEL-TEST, Inc., Friendswood, TX, USA) according to the manufacturer's instructions. RNA concentrations and quality were determined on a NanoDrop spectrophotometer (Thermo Scientific, Wilmington, DE, USA). The quality of RNA was further confirmed by agarose gel electrophoresis by examining the integrity of $18 \mathrm{~S}$ and $28 \mathrm{~S}$ rRNA. RNA samples were stored at $-80^{\circ} \mathrm{C}$ until used for synthesis of CDNA and real-time PCR.

Real-time PCR was used to determine mRNA expression as described previously ${ }^{(38)}$. In the liver, the expression of genes involved in fatty acid synthesis (acetyl-CoA carboxylase, ACC- $\alpha$ ), oxidation (acyl CoA oxidase, ACOX and mediumchain acyl-CoA dehydrogenase, MCAD) and transport (fatty acid transport protein 5, FATP5) was assessed. In the adipose tissue, ACC- $\alpha$, ACOX, the transport protein (adipocyte P2) as well as the GLUT4 were assessed. Cyclophilin was used as the invariant control. Data were subsequently analysed using the $\Delta \Delta C_{\mathrm{T}}$ method (User Bulletin no. 2; Applied Biosystems, 1997; Carlsbad, CA, USA).

\section{Statistical analyses}

Statistical analyses involved computation of means with their standard errors for each of the treatment groups using SAS version 9.1 (SAS Institute, Cary, NC, USA). The significance of treatment effects was analysed by the one-way ANOVA model followed by post boc analysis using Fisher's least square means separation test when $F$ values were significant. Differences were considered significant at $P<0 \cdot 05$.

\section{Results}

Food intake, body and tissue weights, and body composition

There were no significant differences in body weight among the animals before the initiation of dietary treatments (Table 2). Over the course of the 8-week study period, the average food and energy intake of the mice receiving $\mathrm{HF}$ diets were significantly lower than those receiving the control diet (Table 2). Despite these differences in food and energy intake, there were no significant differences in the final body weight among all the groups. The feed efficiency of the HF diet tended $(P=0.0758)$ to be higher compared with the other dietary treatments (Table 2).

Body composition was significantly different despite similar final body weights among the treatment groups after 8 weeks of dietary treatment. The percentage of body fat was higher ( $P=0.0255$ ) while the percentage of fat-free mass was significantly lower in the HF group compared with the other treatment groups (Fig. 1). The two doses of freeze-dried mango had similar effects to rosiglitazone and fenofibrate on reducing the percentage of body fat and the maintaining percentage of fat-free mass.

In agreement with differences in body composition, the mean epididymal fat weight of mice fed the HF diet was approximately twice that of mice receiving the control diet despite their higher energy intake (Table 2). The two doses of freeze-dried mango, similar to fenofibrate and rosiglitazone, protected against the HF diet-induced increase in epididymal fat. There were no significant differences in kidney and spleen weights; however, animals on fenofibrate exhibited

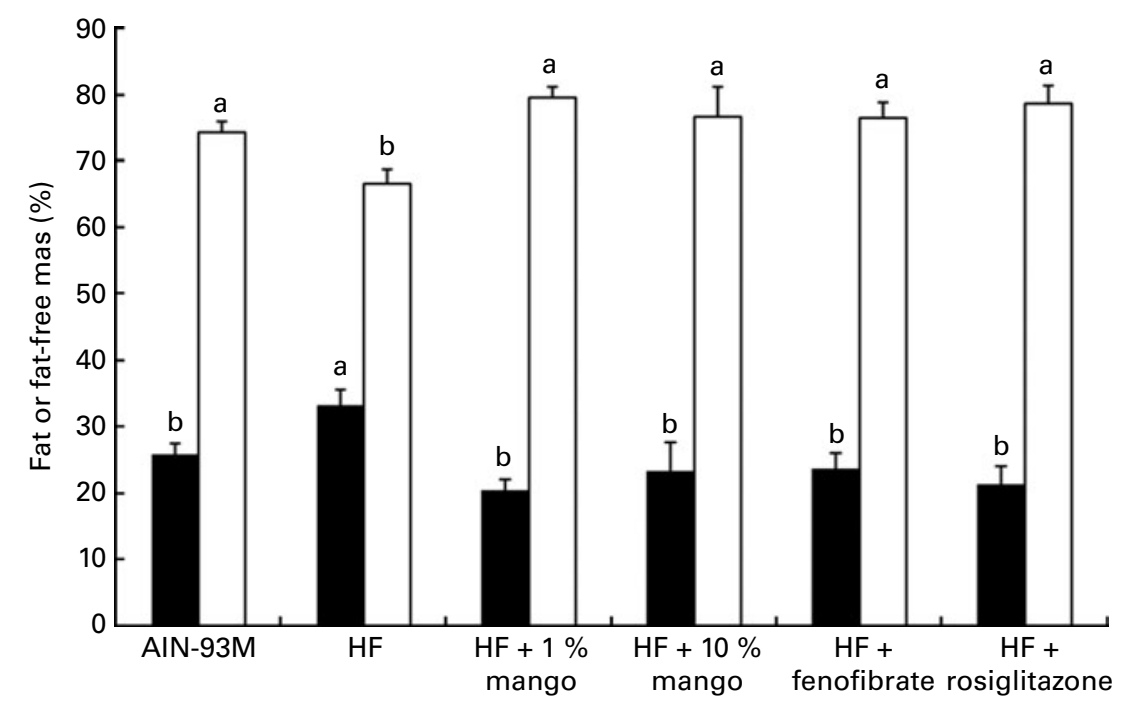

Fig. 1. Effects of freeze-dried mango supplementation compared with rosiglitazone and fenofibrate on percentage of body fat ( $\square$ ) and percentage fat-free mass ( $\square$ ) of mice fed high-fat (HF) diet for 2 months. Values are means with their standard errors (eight to nine per group) represented by vertical bars. ${ }^{\text {a,b }}$ Mean values with unlike letters were significantly different from each other $(P<0.05)$. 
hepatomegaly as evidenced by an increase in wet tissue weight (Table 2).

\section{Glucose tolerance test, fasting plasma glucose and insulin,} and homeostasis model assessment of insulin resistance

To examine glucose tolerance and clearance from the plasma, glucose tolerance tests were performed on animals following fasting for $12 \mathrm{~h}$. No significant differences in blood glucose were observed at 0, 5 and $15 \mathrm{~min}$ post-injection of the glucose solution (Fig. 2(A)). However, after 30, 60 and $120 \mathrm{~min}$, alterations in glucose as a function of diet did occur. Mice receiving the $1 \%$ freeze-dried mango diet had approximately $40-90 \%$ lower blood glucose concentration at 30-120 min compared with those receiving the $\mathrm{HF}$ diet. $\mathrm{HF}+$ rosiglitazone diet reduced blood glucose concentrations at these time points by only about $15-30 \%$ (Fig. 2(A)).

To further characterise the time-dependent changes in blood glucose, we examined the total AUC for each treatment group. Freeze-dried mango supplementation at the $1 \%$ dose was most effective in normalising blood glucose concentrations in response to a $\mathrm{HF}$ diet as indicated by the glucose AUC (Fig. 2(B)). The mean glucose AUC was highest in the $\mathrm{HF}$ group and approximately 35\% lower in the $\mathrm{HF}+1 \%$ freeze-dried mango. Rosiglitazone, fenofibrate, $10 \%$ freezedried mango and the control diet were all statistically similar to the HF diet in terms of their effect on glucose tolerance as shown by the total AUC (Fig. 2(B)).

Fasting plasma glucose concentrations were lowest in the $\mathrm{HF}+$ rosiglitazone group (Table 3 ). The fasting plasma glucose of the mice receiving the $\mathrm{HF}+1 \%$ freeze-dried mango diet, but not those in the $\mathrm{HF}+10 \%$ freeze-dried mango group, was similar to the $\mathrm{HF}+$ rosiglitazone group. Mice in the control and HF groups had similar plasma glucose concentrations. There was no significant difference in plasma insulin concentrations among the treatment groups (Table 3).

The effect of dietary treatments on HOMA-IR corresponded to the changes observed in plasma glucose (Table 3).
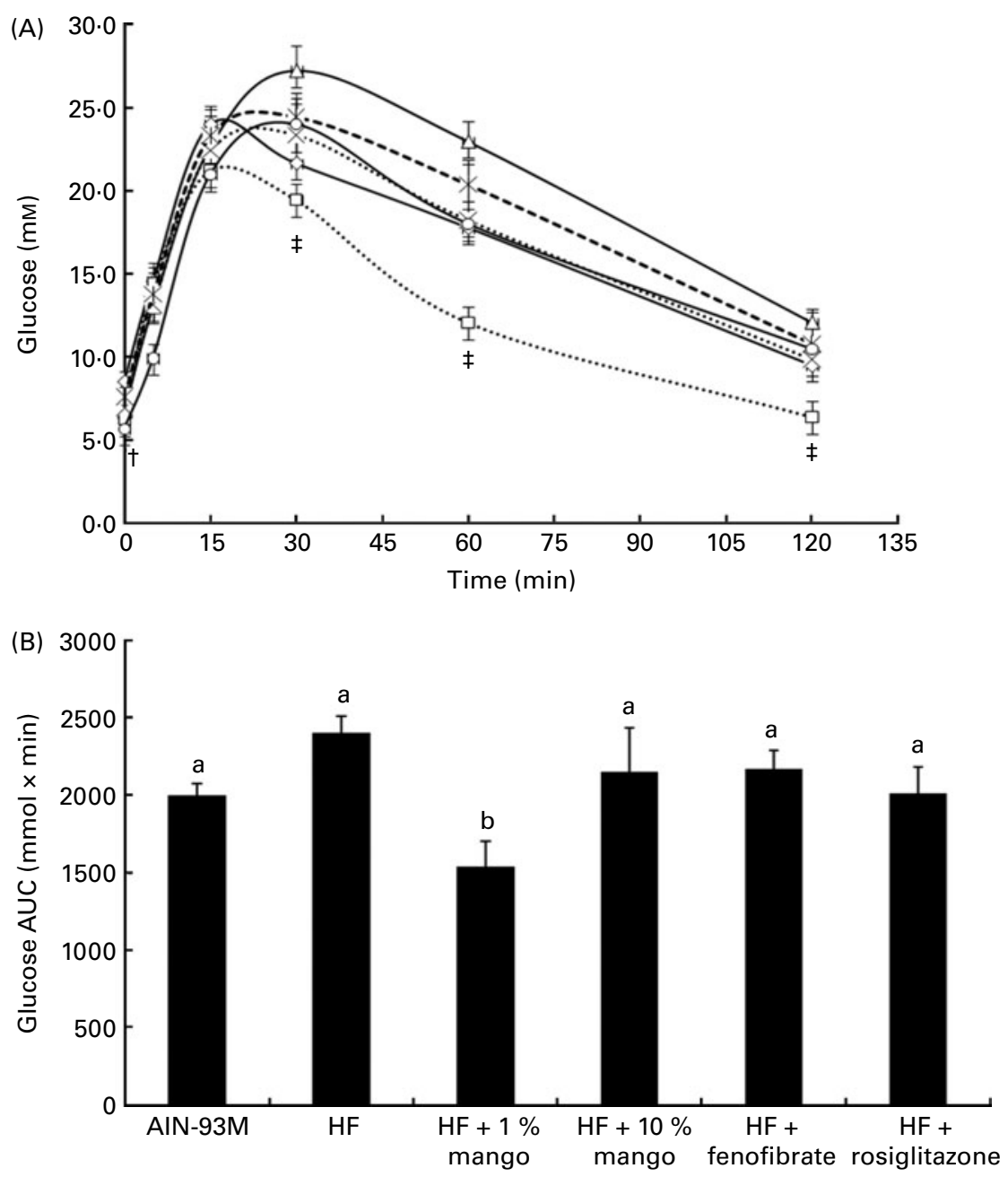

Fig. 2. Effects of freeze-dried mango supplementation compared with rosiglitazone and fenofibrate on (A) blood glucose and (B) area under the curve (AUC) after a glucose tolerance test of mice fed high-fat (HF) diet for 2 months. Values are means with their standard errors (six per group), represented by vertical bars. †Fasting glucose tended to be different at baseline $(P=0.0544)$. $¥$ Mean values were significantly different between treatment groups at these time points. ${ }^{\mathrm{a}, \mathrm{b}}$ Mean values with unlike letters were significantly different from each other $(P<0 \cdot 05) . \prec, \mathrm{AIN}-93 \mathrm{M} ;-\triangleleft, \mathrm{HF} ; \cdot \cdot \square \cdot \cdot, \mathrm{HF}+1 \% \mathrm{mango} ; \cdot \cdot \cdot \cdot \cdot, \mathrm{HF}+10 \% \mathrm{mango}$; -*--., HF + fenofibrate; -O-, HF + rosiglitazone. 
Table 3. Effects of freeze-dried mango supplementation compared with rosiglitazone and fenofibrate on plasma lipids, glucose and insulin concentrations and homeostasis model assessment of insulin resistance (HOMA-IR) of mice fed high-fat (HF) diet for 2 months

(Mean values with their standard errors, eight to nine per group)

\begin{tabular}{|c|c|c|c|c|c|c|c|c|c|c|c|c|}
\hline & \multicolumn{2}{|c|}{ Control } & \multicolumn{2}{|c|}{ HF } & \multicolumn{2}{|c|}{$\begin{array}{l}\mathrm{HF}+1 \% \\
\text { mango }\end{array}$} & \multicolumn{2}{|c|}{$\begin{array}{l}\mathrm{HF}+10 \% \\
\text { mango }\end{array}$} & \multicolumn{2}{|c|}{ HF + fenofibrate } & \multicolumn{2}{|c|}{$\begin{array}{c}\mathrm{HF}+ \\
\text { rosiglitazone }\end{array}$} \\
\hline & Mean & $\mathrm{SE}$ & Mean & $\mathrm{SE}$ & Mean & SE & Mean & SE & Mean & SE & Mean & SE \\
\hline TC $(\mathrm{mmol} / \mathrm{l})$ & $2 \cdot 03^{\mathrm{C}}$ & 0.16 & $2 \cdot 71^{\mathrm{b}}$ & 0.12 & $2 \cdot 35^{\mathrm{b}, \mathrm{c}}$ & 0.14 & $2 \cdot 44^{\mathrm{b}, \mathrm{c}}$ & 0.06 & $3.77^{\mathrm{a}}$ & 0.22 & $2 \cdot 19^{c}$ & 0.10 \\
\hline $\mathrm{HDL}(\mathrm{mmol} / \mathrm{l})$ & $0.85^{c}$ & 0.15 & $1.37^{\mathrm{b}}$ & 0.07 & $0.91^{\mathrm{c}}$ & 0.18 & $1 \cdot 14^{\mathrm{b}, \mathrm{c}}$ & 0.05 & $1.96^{a}$ & 0.15 & $0.76^{c}$ & 0.14 \\
\hline Non-HDL $(\mathrm{mmol} / \mathrm{l})$ & $1 \cdot 18^{\mathrm{b}}$ & 0.1 & $1.34^{\mathrm{b}}$ & 0.07 & $1.44^{\mathrm{b}}$ & 0.20 & $1.30^{\mathrm{b}}$ & 0.07 & $1.82^{\mathrm{a}}$ & 0.13 & $1.42^{\mathrm{b}}$ & 0.13 \\
\hline TAG $(\mathrm{mmol} / \mathrm{l})^{\star}$ & 0.60 & 0.07 & 0.59 & 0.04 & 0.49 & 0.04 & 0.43 & 0.05 & 0.41 & 0.06 & 0.53 & 0.06 \\
\hline NEFA (mEq/l) & $0.31^{b}$ & 0.04 & $0.49^{a}$ & 0.06 & $0.30^{\mathrm{b}}$ & 0.06 & $0.40^{a, b}$ & 0.06 & $0.30^{\mathrm{b}}$ & 0.03 & $0.30^{\mathrm{b}}$ & 0.03 \\
\hline Glucose (mmol/l) & $13 \cdot 1^{\mathrm{a}}$ & 1.4 & $12 \cdot 9^{\mathrm{a}}$ & 0.6 & $8 \cdot 5^{\mathrm{b}, \mathrm{c}}$ & $1 \cdot 2$ & $10 \cdot 0^{\mathrm{b}}$ & 1.2 & $11 \cdot 2^{\mathrm{a}, \mathrm{b}}$ & $1 \cdot 1$ & $6 \cdot 8^{\mathrm{c}}$ & 0.5 \\
\hline Insulin (pmol/l) & $32 \cdot 7$ & 1.7 & $41 \cdot 3$ & 3.4 & 34.4 & 3.4 & $32 \cdot 7$ & 3.4 & $32 \cdot 7$ & 1.7 & $31 \cdot 0$ & 3.4 \\
\hline HOMA-IR & $2 \cdot 98^{\mathrm{a}, \mathrm{b}}$ & 0.39 & $3.36^{a}$ & 0.32 & $2 \cdot 10^{\mathrm{b}, \mathrm{c}}$ & 0.30 & $2 \cdot 10^{\mathrm{b}, \mathrm{c}}$ & 0.27 & $2 \cdot 51^{a, b}$ & 0.32 & $1.38^{\mathrm{c}}$ & 0.20 \\
\hline
\end{tabular}

TC, total cholesterol.

a,b,c Mean values within a row with unlike superscript letters were significantly different from each other $(P<0.05)$.

* Overall $P$ value 0.0764

The degree of insulin resistance was lowest in the $\mathrm{HF}+$ rosiglitazone group as indicated by low HOMA-IR values. Mice receiving the freeze-dried mango diets had HOMA-IR that is similar to the $\mathrm{HF}+$ rosiglitazone group. HOMA-IR was highest in the HF group and the control and $\mathrm{HF}+$ fenofibrate groups were not statistically different from the HF group.

\section{Plasma lipids, leptin and adiponectin}

There were significant differences $(P<0.001)$ in plasma total cholesterol among the groups after 8 weeks of dietary treatment (Table 3). The mice receiving the $\mathrm{HF}+$ fenofibrate diet had plasma total cholesterol concentrations that were approximately $30 \%$ higher compared with the other treatment groups (Table 3). Mice receiving the freeze-dried mango diets had plasma total cholesterol concentrations, which were not statistically different from the control, $\mathrm{HF}+$ rosiglitazone and HF groups (Table 3).
Plasma HDL concentrations were also significantly altered $(P<0 \cdot 001)$ due to treatment. The two doses of freeze-dried mango have a similar effect on plasma HDL concentrations to that of the control and $\mathrm{HF}+$ rosiglitazone diets (Table 3). The HF + fenofibrate group had the highest plasma HDL concentrations and plasma TAG concentrations that were approximately $30 \%$ lower in comparison with the HF group; however, this effect did not reach the level of statistical significance $(P=0.0764)$ (Table 3). Similar to the total cholesterol concentrations, non-HDL-cholesterol was highest in the $\mathrm{HF}+$ fenofibrate group, and no differences were observed between the other treatment groups.

Plasma NEFA concentrations were different $(P=0 \cdot 0318)$ among the treatment groups with the HF group having the highest plasma NEFA concentrations (Table 3). There were no differences in the effects of the $\mathrm{HF}+1 \%$ freeze-dried mango diet on plasma NEFA concentrations compared with the control, $\mathrm{HF}+$ fenofibrate and $\mathrm{HF}+$ rosiglitazone groups. However, the $\mathrm{HF}+10 \%$ freeze-dried mango group had only an intermediate effect.

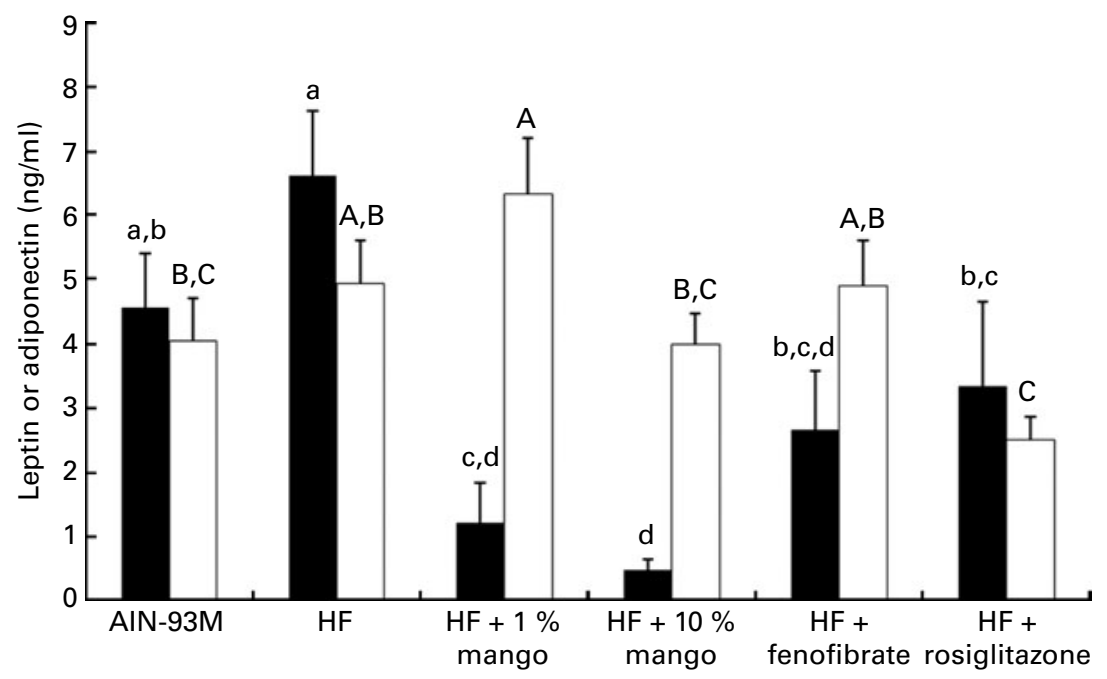

Fig. 3. Effects of freeze-dried mango supplementation compared with rosiglitazone and fenofibrate on plasma leptin ( $\square$ ) and adiponectin ( $\square$ ) concentrations of mice fed high-fat (HF) diet for 2 months. Values are means with their standard errors (eight to nine per group), represented by vertical bars. ${ }^{a, b, c, d}$ Mean values with unlike letters were significantly different $(P<0.05)$. A,B,C Mean values with unlike letters were significantly different $(P<0.05)$. 
Significant differences in plasma leptin $(P=0.0009)$ and adiponectin $(P=0.0119)$ concentrations were observed after 8 weeks of dietary treatment (Fig. 3). Mice consuming the freeze-dried mango diets had significantly lower plasma leptin concentrations than those receiving the control and $\mathrm{HF}$ diets. Rosiglitazone and fenofibrate had effects on plasma leptin concentrations that were statistically similar to the control and the freeze-dried mango groups. Mice that received the $\mathrm{HF}+1 \%$ freeze-dried mango diet had the highest plasma adiponectin concentrations, which were statistically similar to those receiving $\mathrm{HF}$ and $\mathrm{HF}+$ fenofibrate diets. The $\mathrm{HF}+10 \%$ freeze-dried mango diet had a similar effect on plasma adiponectin concentrations to that of control and $\mathrm{HF}+$ rosiglitazone diets.

\section{Gene expression by real-time PCR}

Earlier data ${ }^{(25)}$ indicate that bioactive components of mango might function as a PPAR antagonist; therefore, we examined the extent to which mango may alter gene expression in the liver and adipose tissue. Relative gene expression in the liver for enzymes involved in fatty acid synthesis (ACC- $\alpha$ ), fatty acid transport (FATP5) and $\beta$ oxidation (ACOX1 and MCAD) was examined. Relative to the control diet, mice in the $\mathrm{HF}+10 \%$ freeze-dried mango group had the lowest while $\mathrm{HF}+$ fenofibrate had the highest expression of the lipogenic gene ACC- $\alpha$ (Table 4). No differences in the relative mRNA expression of ACC $\alpha$ were observed in mice receiving either the control, HF or $1 \%$ freeze-dried mango diets (Table 4).

To determine the extent to which alterations in plasma lipids were associated with enhanced fatty acid uptake, the relative mRNA abundance of the transport protein, FATP5, was examined in the liver. The HF + fenofibrate group had the highest gene expression of FATP5. The two doses of freeze-dried mango had similar liver gene expression of FATP5 to rosiglitazone and significantly lower than the control, $\mathrm{HF}$ and $\mathrm{HF}+$ fenofibrate groups (Table 4)
The effect of mango on gene expression in the liver enzymes involved in fatty acid oxidation (ACOX and MCAD) is also shown in Table 4. There were no alterations at the transcriptional level of MCAD and ACOX resulting from 8 weeks of consuming a HF diet. The two doses of freezedried mango, similar to rosiglitazone, decreased the relative expression of MCAD in the liver, compared with the control, $\mathrm{HF}$ and $\mathrm{HF}+$ fenofibrate groups. Mice receiving the $\mathrm{HF}+$ fenofibrate diet had the highest ACOX gene expression while $10 \%$ freeze-dried mango had the lowest.

The gene expression of ACC- $\alpha$, ACOX, GLUT4 and fatty acid binding protein (adipocyte P2) was also investigated in the adipose tissue (Table 4). No significant differences in the expression of these genes were observed. However, adipocyte $\mathrm{P} 2$ tended $(P=0.0598)$ to be higher in the HF + rosiglitazone, $\mathrm{HF}+10 \%$ freeze-dried mango and control groups.

\section{Discussion}

The present study investigated the effect of two doses (1 and $10 \%)$ of freeze-dried mango pulp on body composition and blood glucose and lipids in mice fed a HF diet. Moreover, the effects of freeze-dried mango were compared with those of fenofibrate and rosiglitazone, two drugs commonly used in modulating lipid profile and lowering blood glucose, respectively. In the present study, we did not observe differences in weekly or final body weights among the treatment groups. The lack of difference in the final body weights was likely due to the relatively lower food and subsequent energy intake in mice receiving HF diets compared with those receiving the control diet. Despite the lower food intake of mice in the HF group, the feed efficiency of the HF diet tended $(P=0.0758)$ to be approximately $40 \%$ higher in comparison with the other dietary treatments.

Even though no differences were observed in the final body weights among the groups, alterations in body composition were demonstrated. Consumption of a HF diet significantly increased the percentage of body fat and reduced the

Table 4. Effects of freeze-dried mango supplementation compared with rosiglitazone and fenofibrate on relative mRNA of genes involved in lipid and glucose metabolism in the liver and adipose tissue of mice fed high-fat diet (HF) for 2 months

(Mean values with their standard errors, six per group)

\begin{tabular}{|c|c|c|c|c|c|c|c|c|c|c|c|c|}
\hline & \multicolumn{2}{|c|}{ Control } & \multicolumn{2}{|c|}{$\mathrm{HF}$} & \multicolumn{2}{|c|}{$\mathrm{HF}+1 \%$ mango } & \multicolumn{2}{|c|}{$\begin{array}{c}\mathrm{HF}+10 \% \\
\text { mango }\end{array}$} & \multicolumn{2}{|c|}{$\begin{array}{l}\mathrm{HF}+\text { feno- } \\
\text { fibrate }\end{array}$} & \multicolumn{2}{|c|}{$\begin{array}{l}\mathrm{HF}+\text { rosi- } \\
\text { glitazone }\end{array}$} \\
\hline & Mean & SE & Mean & SE & Mean & SE & Mean & SE & Mean & SE & Mean & SE \\
\hline \multicolumn{13}{|l|}{ Liver } \\
\hline ACC- $\alpha$ & $1.0^{\mathrm{b}}$ & 0.08 & $0.78^{b, c}$ & 0.09 & $0.78^{b, c}$ & 0.07 & $0.45^{d}$ & 0.02 & $1.46^{\mathrm{a}}$ & 0.09 & $0.59^{\mathrm{c}, \mathrm{d}}$ & $0 \cdot 10$ \\
\hline ACOX & $1.0^{\mathrm{b}}$ & $0 \cdot 12$ & $0 \cdot 80^{b, c}$ & 0.10 & $0.71^{\mathrm{b}, \mathrm{c}}$ & 0.08 & $0.38^{c}$ & 0.07 & $2 \cdot 60^{\mathrm{a}}$ & 0.44 & $0.60^{b, c}$ & 0.07 \\
\hline MCAD & $1.0^{\mathrm{b}}$ & 0.09 & $0.94^{\mathrm{b}}$ & 0.10 & $0.58^{\mathrm{C}}$ & 0.06 & $0.38^{\mathrm{C}}$ & 0.04 & $2 \cdot 34^{\mathrm{a}}$ & 0.17 & $0.58^{\mathrm{c}}$ & 0.09 \\
\hline FATP5 & $1.0^{\mathrm{b}}$ & 0.12 & $1.04^{a, b}$ & 0.06 & $0.65^{c}$ & 0.09 & $0.50^{c}$ & 0.06 & $1 \cdot 24^{\mathrm{a}}$ & 0.08 & $0.65^{c}$ & 0.09 \\
\hline \multicolumn{13}{|c|}{ Adipose tissue } \\
\hline ACC- $\alpha$ & $1 \cdot 0$ & 0.41 & $1 \cdot 2$ & 0.42 & 0.99 & 0.32 & 0.72 & 0.29 & $2 \cdot 20$ & 0.62 & 1.35 & 0.30 \\
\hline ACOX & $1 \cdot 0$ & 0.46 & 0.49 & 0.16 & 0.65 & 0.24 & 0.52 & 0.18 & $2 \cdot 04$ & 0.69 & 0.80 & 0.31 \\
\hline GLUT4 & 1.0 & 0.45 & 0.52 & 0.22 & 0.60 & 0.24 & 0.54 & 0.21 & 0.80 & 0.14 & 1.08 & 0.28 \\
\hline $\mathrm{aP}^{*}{ }^{*}$ & 1.0 & 0.22 & 0.58 & 0.17 & 0.82 & 0.36 & 1.04 & 0.38 & 0.64 & 0.19 & $1 \cdot 8$ & 0.32 \\
\hline
\end{tabular}

ACC- $\alpha$, acetyl-CoA carboxylase; ACOX, acyl CoA oxidase; MCAD, medium-chain acyl-CoA dehydrogenase; FATP5, fatty acid transport protein; aP2, adipocyte P2.

a,b,c,d Mean values within a row with unlike superscript letters were significantly different from each other $(P<0.05)$

*Overall $P$ value 0.0598 . 
percentage of fat-free mass. The two doses of freeze-dried mango had comparable effects to those of rosiglitazone and fenofibrate in modulating body composition. Consistent with our findings on body composition with X-ray absorptiometry, we have also observed an increase in epididymal fat mass and in plasma leptin concentrations due to the HF diet. Studies have shown that HF diets elevate circulating leptin and treatments that decreased or slowed the development of obesity are associated with reductions in plasma leptin concentrations ${ }^{(39,40)}$. In the present study, the increase in epididymal fat mass and leptin concentrations associated with the HF diet was prevented by the two doses of freeze-dried mango, fenofibrate and rosiglitazone. To our knowledge, this is the first animal study demonstrating the effectiveness of freeze-dried mango pulp in preventing the increase in adiposity and plasma leptin concentrations due to a HF diet.

The present findings on the effects of fenofibrate and rosiglitazone on adiposity are consistent with previously published animal studies ${ }^{(34,41-44)}$. Fenofibrate, a PPAR- $\alpha$ agonist and hypolipidaemic drug, regulates the synthesis and clearance of lipoprotein and energy dissipation by inducing the expression of uncoupling protein in the hepatic mitochondria $^{(45)}$. Thiazolidinediones such as rosiglitazone are involved in adipogenesis, adipocyte differentiation, and favour the formation of smaller adipocytes ${ }^{(46)}$. Most studies have shown that thiazolidinediones induce weight gain in diabetic animal models, but the extent of weight gain depends on the dose, the age of the animal and the animal model used ${ }^{(47)}$. The relatively low dose of rosiglitazone used in the present study may be sufficient to augment the induction of a lean phenotype as observed by Kuda et al. ${ }^{(44)}$.

The present study demonstrated that 1 and $10 \%$ freezedried mango supplementation, similar to rosiglitazone and fenofibrate, reduced adipose tissue mass to that of the mice fed the control diet (AIN-93M). We cannot explain the observed effect of freeze-dried mango on adipose tissue based on the results of our gene expression analyses. The degree to which freeze-dried mango acts through a mechanism involving either PPAR- $\alpha$ or PPAR- $\gamma$ in preventing the increase in adipose tissue due to HF diet warrants further investigation. However, it should be noted that an in vitro study by Wilkinson et al. ${ }^{(25)}$ showed that the phenolic compounds found in mango (i.e. mangiferin) exhibit a trend towards the activation of PPAR, while quercetin and the aglycone derivative of mangiferin, norathyriol, inhibits the activation of PPAR. Mango pulp contains numerous bioactive compounds that could potentially act as PPAR agonists and antagonists. As shown in Table 1, some of the bioactive compounds in the freeze-dried mango used in the study include ascorbic acid, $\beta$-carotene, gallotanin, mangiferin and ellagic $\operatorname{acid}^{(28)}$. Whether the amount of the bioactive compounds in the mango used in the present study will be sufficient to act as PPAR agonist or antagonist in our animal model, similar to that observed in the in vitro studies by Wilkinson et al. ${ }^{(25)}$, is not clear at this time. Moreover, whether the concentration of freeze-dried mango that we have used in the present study is reasonable for human consumption needs to be investigated in future studies. Considering food intake and body weight, the $1 \%$ dose of freeze-dried mango used in the present animal study is equivalent to a dose of $1 \mathrm{~g}$ of freeze-dried mango/kg body weight, which translates to consuming approximately two and a half fresh mango fruit ( $475 \mathrm{~g}$ with $85 \%$ moisture content) or $70 \mathrm{~g}$ of freeze-dried mango daily by a $70 \mathrm{~kg}$ individual.

In the present study, we also examined the effects of freezedried mango on glucose homeostasis by performing glucose tolerance tests, measuring fasting glucose and insulin concentrations, and calculating AUC and HOMA-IR as an index of insulin resistance. Glucose tolerance tests demonstrated that freeze-dried mango (i.e. $1 \%$ dose) exhibited glucose-lowering properties compared with the other dietary treatments and were more pronounced than those observed with rosiglitazone. By comparison, the AUC of the $10 \%$ freeze-dried mango dose was comparable with the rosiglitazone group, but higher than the $1 \%$ freeze-dried mango dose. In addition to the glucose tolerance test, we also calculated HOMA-IR to approximate insulin resistance. The present findings show that the mice receiving the freeze-dried mango diets, similar to rosiglitazone, had lower insulin resistance as indicated by HOMA-IR. Insulin resistance results in a reduced response of peripheral tissues to insulin action resulting in hyperglycaemic state and has been recognised as an integral part of the metabolic syndrome.

The present findings are the first to demonstrate the effectiveness of freeze-dried mango pulp in modulating a hyperglycaemic state induced by the consumption of a HF diet. Relatively few studies have examined the glucose-lowering properties of freeze-dried mango, and most of these studies have focused not on the flesh or pulp but instead on the extract of the stem bark or leaves, which is rich in the phenolic compound mangiferin ${ }^{(20-23)}$. The extract of the stem bark and leaves of mango was shown to effectively lower blood glucose in streptozotocin-induced diabetic rats ${ }^{(20,21)}$ and glucoseinduced hyperglycaemia in rats and mice ${ }^{(22,23)}$. In terms of the mango pulp, two clinical studies have examined the effects of mango pulp on glucose levels ${ }^{(48,49)}$. These studies compared the postprandial glucose and insulin responses associated with mango to other tropical fruits in patients with type 2 diabetes. Both of these studies demonstrate that mango is similar to or better than the other tropical fruits (sapota, banana, durian, rambutan and pineapple) in improving the glucose response in type 2 diabetics. Overall, the present findings and those from other animal studies ${ }^{(20-23)}$ and the limited clinical trials ${ }^{(47,48)}$ suggest that mango pulp and its bioactive component(s) may be used to reduce blood glucose concentrations.

It is interesting to note that in the present study, we found the $1 \%$ freeze-dried mango dose was more effective in modulating glucose than the $10 \%$ dose. The phenomenon that lower doses can be more effective than the higher doses has been observed with other phenolic compounds. For example, blueberry purified anthocyanin at a dose of $0.2 \mathrm{mg} / \mathrm{ml}$ added to drinking-water was more effective than $1.0 \mathrm{mg} / \mathrm{ml}$ in modulating glucose and other clinical parameters of mice fed HF $\operatorname{diet}^{(39)}$. A dose-response study investigating the anti-diabetic potential of Citrus sinensis (12.5, 25, 50 and $100 \mathrm{mg} / \mathrm{kg}$ ) and 
Punica granatum (100, 200, 300 and $400 \mathrm{mg} / \mathrm{kg}$ ) peel extracts in alloxan-treated male mice demonstrated that the most effective dose in lowering blood glucose is 25 and $200 \mathrm{mg} / \mathrm{kg}$ for C. sinensis and P. granatum peel extract, respectively ${ }^{(50)}$. Moreover, a study by Marugundanan et al. ${ }^{(21)}$ demonstrated that mangiferin at $10 \mathrm{mg} / \mathrm{kg}$ is as effective as the $20 \mathrm{mg} / \mathrm{kg}$ dose for its anti-diabetic, anti-hyperlipidaemic and anti-atherogenic activities in streptozotocin-diabetic rats. These findings demonstrate the need to identify the optimal dose of foods and its bioactive compounds that exert a health benefit and not to work under the assumption that more is better.

The mechanism by which freeze-dried mango exerts glucose-lowering properties is not known at this time. The hypoglycaemic activity of the mango leaves aqueous extract has been attributed to the stimulation of the pancreatic $\beta$-cells to secrete insulin and to the reduced intestinal absorption of glucose ${ }^{(22)}$. However, the present findings show no differences in circulating steady-state insulin concentrations among the groups. Moreover, the results of our gene expression analysis demonstrate that freeze-dried mango had no effect on the expression of GLUT4 in the adipose tissue, which suggests that freeze-dried mango did not increase glucose uptake in this tissue. Future studies should examine how freeze-dried mango and its bioactive component(s) lower blood glucose concentrations.

In addition to lowering plasma glucose concentrations, freeze-dried mango had modest effects on plasma total cholesterol in this animal model. No differences were observed in the total cholesterol of mice receiving the freeze-dried mango-supplemented diets or rosiglitazone compared with the control diet. However, plasma total cholesterol of the freeze-dried mango group was not statistically different from those receiving the HF diet. Interestingly, fenofibrate produced an increase in plasma total cholesterol and a slight reduction in TAG, which is not consistent with the present findings of earlier studies ${ }^{(51,52)}$. However, Arai et $a l .{ }^{(53)}$ and Declercq et $a l .{ }^{(54)}$ also observed an increase in total cholesterol concentrations with fenofibrate in $\mathrm{C} 57 \mathrm{BL} / 6$ mice. The increase in total cholesterol due to fenofibrate is attributed to an elevation in HDL-cholesterol concentrations, which we have also observed in the present study ${ }^{(53,54)}$. Although the present findings on the effects of fenofibrate on circulating lipids are different from those published in the literature ${ }^{(51,52)}$, the alterations in hepatic gene expression of ACC $\alpha$, ACOX1, FATP5, LPL and MCAD were consistent with other studies ${ }^{(34,55)}$. Whether freeze-dried mango acts similarly to fenofibrate in modulating lipids is not clear at this time.

Overall, a low-dose freeze-dried mango (1\%,w/w) was more effective in a lowering blood glucose concentration than the hypoglycaemic drug, rosiglitazone $(50 \mathrm{mg} / \mathrm{kg} \mathrm{diet})$, in mice consuming a HF diet. Moreover, freeze-dried mango, similar to rosiglitazone, favourably alters body composition by reducing the percentage of body fat. Further studies are needed to focus on identifying the bioactive compound(s) and the mechanism(s) involved in glucose-metabolism and adiposity that could explain the effect of freeze-dried mango. Clinical studies are also warranted to determine whether these same glucose-modulating and anti-obesity properties of freeze-dried mango can be afforded to human subjects. Moreover, whether supplementing with fresh mango will offer the same benefits needs to be examined.

\section{Acknowledgements}

The authors would like to acknowledge funding from the National Mango Board and Oklahoma State University, College of Human Environmental Sciences, start-up support. E. A. L., S. K., P. P.-V., S. L. C., and B. J. S. designed the study; W. L., S. K. P. and A. B. conducted the research; E. A. L., W. L., S. K., P. P.-V., S. L. C. and B. J. S. analysed the data; E. A. L., W. L., S. K., S. L. C. and B. J. S. wrote the manuscript. E. A. L. had primary responsibility for the final content. All authors read and approved the final manuscript. The authors do not have any conflict of interest.

\section{References}

1. Flegal KM, Carroll MD, Ogden CL, et al. (2010) Prevalence and trends in obesity among US adults. 1999-2008. JAMA 303, 235-241.

2. Popkin BM (2001) The nutrition transition and obesity in the developing world. J Nutr 31, 871S-873S.

3. American Heart Association (2010) Heart and stroke facts: statistical update. 2010 Report. http://www.americanheart. org/downloadable/heart/1265665152970DS-3241\%20HeartStroke Update_2010.pdf

4. American Heart Association. International cardiovascular disease statistics. Statistical fact sheet 2009 update. http://americanheart. org/downloadable/heart/1236204012112INTL.pdf

5. Mathieu P, Lemieux I \& Després JP (2010) Obesity, inflammation, and cardiovascular risk. Clin Pharmacol Ther $\mathbf{8 7}$, 407-416.

6. Siri-Tarino PW, Sun Q, Hu FB, et al. (2010) Saturated fat, carbohydrate, and cardiovascular disease. Am J Clin Nutr 91, 502-509.

7. Hanna-Moussa A, Gardner MJ, Kurukulasuriya LR, et al. (2009) Dysglycemia/prediabetes and cardiovascular risk factors. Rev Cardiovasc Med 10, 202-208.

8. Robinson E \& Grieve DJ (2009) Significance of peroxisome proliferator-activated receptors in the cardiovascular system in health and disease. Pharmacol Ther 122, 246-263.

9. Wang YX (2010) PPARs: diverse regulators in energy metabolism and metabolic diseases. Cell Res 20, 124-137.

10. Latruffe N \& Vamecq J (1997) Peroxisome proliferators and peroxisome proliferator activated receptors as regulators of lipid metabolism. Biochimie 79, 81-94.

11. Kalaitzidis RG, Sarafidis PA \& Bakris GL (2009) Effects of thiazolidinediones beyond glycaemic control. Curr Pharm Des 15, 529-536.

12. Roberts WC (1989) Safety of fenofibrate - US and worldwide experience. Cardiology 76, 169-179.

13. Ullah MF \& Khan MW (2008) Food as medicine: potential therapeutic tendencies of plant derived polyphenolic compounds. Asian Pac J Cancer Prev 9, 187-195.

14. Jew S, AbuMweis SS \& Jones PJ (2009) Evolution of the human diet: linking our ancestral diet to modern functional foods as a means of chronic disease prevention. $J$ Med Food 12, 925-934. 
15. Jayaprakasam B, Vareed SK, Olson LK, et al. (2005) Insulin secretion by bioactive anthocyanins and anthocyanidins present in fruits. J Agric Food Chem 53, 28-31.

16. Ware WR (2009) Nutrition and the prevention and treatment of cancer: association of cytochrome P450 CYP1B1 with the role of fruit and fruit extracts. Integr Cancer Ther 8, 22-28.

17. Wu H, Dai Q, Shrubsole MJ, et al. (2009) Fruit and vegetable intakes are associated with lower risk of colorectal adenomas. J Nutr 139, 340-344.

18. Iriti M \& Faoro F (2006) Grape phytochemicals: a bouquet of old and new nutraceuticals for human health. Med Hypotheses $\mathbf{6 7}, 833-838$.

19. U.S. Department of Agriculture \& Agricultural Research Service (2005) USDA National nutrient database for standard reference, Release 18. http://www.ars.usda.gov/ba/bhnrc/ndl

20. Ojewole JA (2005) Antiinflammatory, analgesic and hypoglycemic effects of Mangifera indica Linn. (Anacardiaceae) stem-bark aqueous extract. Methods Find Exp Clin Pharmacol 27, 547-554

21. Muruganandan S, Srinivasan K, Gupta S, et al. (2005) Effect of mangiferin on hyperglycemia and atherogenicity in streptozotocin diabetic rats. J Ethnopharmacol 97, 497-501.

22. Aderibigbe AO, Emudianughe TS \& Lawal BAS (2001) Evaluation of the antidiabetic action of Mangifera indica in mice. Phytother Res 15, 456-458.

23. Aderibigbe AO, Emudianughe TS \& Lawal BAS (1999) Antihyperglycaemic effect of Mangifera indica in rat. Phytother Res 13, 504-507.

24. Percival SS, Talcott ST, Chin ST, et al. (2006) Neoplastic transformation of BALB/3T3 cells and cell cycle of HL-60 cells are inhibited by mango (Mangifera indica $\mathrm{L}$.) juice and mango juice extracts. J Nutr 136, 1300-1304

25. Wilkinson AS, Monteith GR, Shaw PN, et al. (2008) Effects of the mango components mangiferin and quercetin and the putative mangiferin metabolite norathyriol on the transactivation of peroxisome proliferator-activated receptor isoforms. I Agric Food Chem 56, 3037-3042.

26. Reeves PG, Nielsen FH \& Fahey GC Jr (1993) AIN-93 purified diets for laboratory rodents: final report of the American Institute of Nutrition ad hoc Writing Committee on the reformulation of the AIN-76A rodent diet. J Nutr 123, 1939-1951.

27. Molnar J, Yu S, Mzhavia N, et al. (2005) Diabetes induces endothelial dysfunction but does not increase neointimal formation in high-fat diet fed C57BL/6J mice. Circ Res 96 , 1178-1184.

28. Manthey J \& Perkins-Veazie P (2009) Influences of harvest date and location on the levels of beta-carotene, ascorbic acid, total phenols, the in vitro antioxidant capacity, and phenolic profiles of five commercial varieties of mango (Mangifera indica L.). J Agric Food Chem 57, 10825-10830.

29. Lucas EA, Juma S, Stoecker BJ, et al. (2000) Prune suppresses ovariectomy-induced hypercholesterolemia in rats. $J$ Nutr Biochem 11, 255-259.

30. Prior RL, Wu X, Gu L, et al. (2008) Whole berries versus berry anthocyanins: interactions with dietary fat levels in the C57BL/6J mouse model of obesity. J Agric Food Chem 56, 647-653

31. Dulebohn RV, Yi W, Srivastava A, et al. (2008) Effects of blueberry (Vaccinium ashei) on DNA damage, lipid peroxidation, and phase II enzyme activities in rats. J Agric Food Chem 56, 11700-11706

32. Bobek P, Ginter E, Jurcovicova M, et al. (1990) Effect of dehydrated apple products on the serum and liver lipids in Syrian hamsters. Nabrung 34, 783-789.
33. Chao L, Marcus-Samuels B, Mason MM, et al. (2000) Adipose tissue is required for the antidiabetic, but not for the hypolipidemic, effect of thiazolidinediones. J Clin Invest 106, 1221-1228.

34. Guerre-Millo M, Gervois P, Raspé E, et al. (2000) Peroxisome proliferator-activated receptor alpha activators improve insulin sensitivity and reduce adiposity. J Biol Chem $\mathbf{2 7 5}$, $16638-16642$

35. Tai MM (1994) A mathematical model for the determination of total area under glucose tolerance and other metabolic curves. Diabetes Care 17, 152-154.

36. Matthews DR, Hosker JP, Rudenski AS, et al. (1985) Homeostasis model assessment: insulin resistance and beta-cell function from fasting plasma glucose and insulin concentrations in man. Diabetologia 28, 412-419.

37. Lee S, Muniyappa R, Yan X, et al. (2008) Comparison between surrogate indexes of insulin sensitivity and resistance and hyperinsulinemic euglycemic clamp estimates in mice. Am J Physiol Endocrinol Metab 294, E261-E270.

38. Valasek MA, Clarke SL \& Repa JJ (2007) Fenofibrate reduces intestinal cholesterol absorption via PPARalpha-dependent modulation of NPC1L1 expression in mouse. J Lipid Res 48, 2725-2735.

39. Prior RL, Wilkes S, Rogers T, et al. (2010) Purified blueberry anthocyanins and blueberry juice alter development of obesity in mice fed an obesogenic high-fat diet. J Agric Food Chem 58, 3970-3976.

40. Fukumitsu S, Aida K, Ueno N, et al. (2008) Flaxseed lignin attenuates high-fat diet-induced fat accumulation and induces adiponectin expression in mice. Br J Nutr $\mathbf{1 0 0}$, 669-676

41. Yoon M, Jeong S, Nicol CJ, et al. (2002) Fenofibrate regulates obesity and lipid metabolism with sexual dimorphism. Exp Mol Med 34, 481-488.

42. Mancini FP, Lanni A, Sabatino L, et al. (2001) Fenofibrate prevents and reduced body weight gain and adiposity in diet-induced obese rats. FEBS Lett 491, 154-158.

43. Nagai Y, Nishio Y, Nakamura T, et al. (2002) Amelioration of high fructose-induced metabolic derangements by activation of PPARalpha. Am J Physiol Endocrinol Metab 282, E1180-E1190.

44. Kuda O, Jelenik T, Jilkova Z, et al. (2009) n-3 fatty acids and rosiglitazone improve insulin sensitivity through additive stimulatory effects on muscle glycogen synthesis in mice fed a high-fat diet. Diabetologia 52, 941-951.

45. Caldwell J (1989) The biochemical pharmacology of fenofibrate. Cardiology 76, 33-41.

46. Walker GE, Marzullo P, Verti B, et al. (2008) Subcutaneous abdominal adipose tissue subcompartments: potential role in rosiglitazone effects. Obesity (Silver Spring) 16, 1983-1991.

47. Larsen TM, Toubro S \& Astrup A (2003) PPARgamma agonists in the treatment of type II diabetes: is increased fatness commensurate with long-term efficacy? Int J Obes Relat Metab Disord 27, 147-161.

48. Contractor Z, Hussain F \& Jabbar A (1999) Postprandial glucose response to mango, banana and sapota. J Pak Med Assoc 49, 215-216

49. Roongpisuthipong C, Banphotkasem S, Komindr S, et al. (1991) Postprandial glucose and insulin responses to various tropical fruits of equivalent carbohydrate content in non-insulin-dependent diabetes mellitus. Diabetes Res Clin Pract 14, 123-131.

50. Parmar H \& Kar A (2007) Antidiabetic potential of Citrus sinensis and Punica granatum peel extracts in alloxantreated male mice. Biofactors 31, 17-24. 
51. Xie W, Nie Y, Du L, et al. (2007) Preventive effects of fenofibrate on insulin resistance, hyperglycaemia, visceral fat accumulation in NIH mice induced by small-dose streptozotocin and lard. Pharmacol Res 55, 392-399.

52. Srivastava RA (2009) Fenofibrate ameliorates diabetic and dyslipidemic profiles in KKAy mice partly via down-regulation of 11beta-HSD1, PEPCK and DGAT2. Comparison of PPARalpha, PPARgamma, and liver $\times$ receptor agonists. Eur J Pharmacol 607, 258-263.
53. Arai T, Kim HJ, Chiba H, et al. (2009) Interaction of fenofibrate and fish oil in relation to lipid metabolism in mice. J Atheroscler Thromb 16, 283-291.

54. Declercq V, Yeganeh B, Moshtaghi-Kashanian GR, et al. (2005) Paradoxical effects of fenofibrate and nicotinic acid in apo E-deficient mice. J Cardiovasc Pharmacol 46, 18-24.

55. Mancini FP, Lanni A, Sabatino L, et al. (2001) Fenofibrate prevents and reduces body weight gain and adiposity in diet-induced obese rats. FEBS Lett 491, 154-158. 